\title{
Lakes as an archive of the region ecological state information
}

\author{
Svetlana Shalnova ${ }^{1, *}$ and Vladimir Kulakov ${ }^{2}$ \\ ${ }^{1}$ Peter the Great St.Petersburg Polytechnic University (SPbPU), Polytechnic str. 29, 195251, Saint- \\ Petersburg, Russia \\ ${ }^{2}$ Financial university under the Government of the Russian Federation, 125993, 49, Leningradsky \\ Prospekt, Moscow, Russia
}

\begin{abstract}
The study's results of various lakes located on the border of the forest and forest-steppe areas of Siberia, Altai and Kazakhstan are presented in the article. This research was carried out by participants of the international Russian-German expedition "Following the Traces of Alexander von Humboldt in Western Siberia, Altai and East Kazakhstan", devoted to the 250th anniversary of the birth of the outstanding scientist and the 190th anniversary of his expedition to the Russian Empire. The results of geochemical and pollen analyses of water samples and lake sediments are presented. An assessment of the ecological state of the lakes is given, as well as a rapid assessment of the ecological state of the studied regions.
\end{abstract}

\section{Introduction}

The international Russian-German expedition "Following the Traces of Alexander von Humboldt in Western Siberia, Altai and East Kazakhstan" was held as a part of a joint project of the St. Petersburg Mining University, Freiberg Mining Academy and the St. Petersburg Association of Scientists and Scholars in May - June 2019. It was devoted to the 250th anniversary of the birth of an outstanding scientist and the 190th anniversary of his expedition to the Russian Empire. Various investigations, including lakes study, were conducted during the expedition. The aquatic ecosystem is a natural object, which is the unity of the environment and its biota. Therefore, to assess the state of the lake ecosystem, it is necessary to know the indicators of water as a habitat and the indicators of the biotic (organism) part of the ecosystem. Lake sediments are also very important to assess the state of a water body. Lake sediments of lakes are a kind of depositing medium and are able to accumulate the information of the ecological state of the entire catchment area of the lake. Contaminants entering water bodies are a source of primary pollution [1-3]. Then lake sediments gradually accumulate these contaminants and become a source of secondary pollution of water bodies. Heavy metals are among of the most dangerous contaminants that are intensively accumulated in the lake sediments. To make an assessment of the lakes ecological state, water and lake sediments were sampled, followed by chemical and sporepollen analysis.

\footnotetext{
* Corresponding author: sveta-net07@mail.ru
} 


\section{Literature review}

The expedition participants carried out studies of various lakes located on the border of the forest and forest-steppe areas of Siberia, Altai Region and Kazakhstan. The sampling points are shown in figure 1.

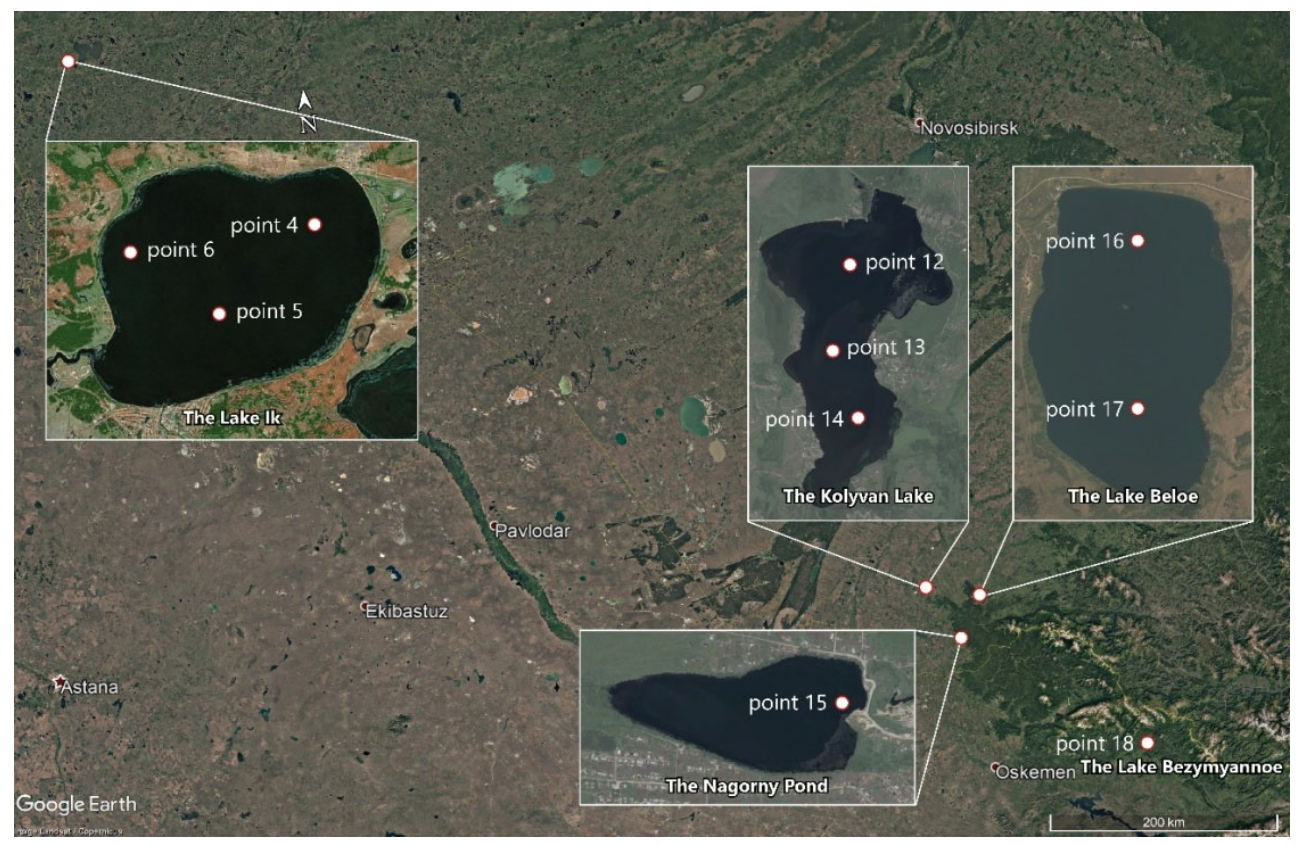

Fig. 1. Location map with sampling points.

Sampling points numbered 4, 5 and 6 were situated on Lake Ik (fig.1), which is located in the Krutinsky district of the Omsk region, in the south of the West Siberian Plain, in the interstream area of Ishim and Irtysh. The Ik is part of The Great Lakes Krutinsky (the Ik, the Saltaim, the Tenis), belonging to the Irtysh lake-river system. According to the state water register, the area of the water mirror of the lake is $71.4 \mathrm{~km}^{2}$, the average depth is 2.7 $\mathrm{m}$. The Ik is the 4th lake of the Omsk region and the 160th lake of Russia in the area of the water mirror. The coastline is $22 \mathrm{~km}$ long. The northeastern and eastern shores are subject to constant. The bottom of the lake is flat and silty. Water supply of the lake is supported mainly by tributaries - River Yaman and River Krutikha, as well as due to precipitation. The mouth of River Krutikha, which flows into the lake from the south, is strongly silted up, and the water flow is insignificant in dry periods. Only one River Kiterma flows out of the Ik. There is a peasant-type dam on the source of the river, which supports the water horizon in the lake. It also connects Lake Ik with Lake Saltaim. For the time being, the Ik suffers from recreational load, which takes a step for the worse of its condition.

Sampling points numbered 12, 13 and 14 were situated on Lake Kolyvan (fig.1). It's located in the Zmeinogorsk district of the Altai Region of Russia on the border of the PreAltai Plain and at the foot of the northern slope of the Kolyvan Ridge. The lake has an irregular shape. It stretches for four kilometers from north to south and for two kilometers from west to east. The average depth of the lake is 3 meters. The total length of the coastline is $11.5 \mathrm{~km}$. The bottom of the lake is lined with silt. The thickness of the sludge reaches one meter in some places. The lake is fed by numerous underwater sources [4].

Lake Kolyvan is a natural monument of Regional importance, but over the past thirty years it has been experienced a significant and constantly increasing anthropogenic load. 
One of the main sources of pollution, apart from agricultural production, is unorganized recreational activities [5]. Fifteen years ago, in the warm season, the daily density of holidaymakers on the coast of Lake Kolyvan reached 240-300 man-hour per hectare, and on weekends - 420-490 man-hour per hectare, whereas permissible load on this lake is 365 man-hour per hectare (according to the calculations of N.G. Prudnikova). Since then, the recreational load on the lake has increased significantly [6, 7].

Sample number 15 was collected from Pond Nagorny (fig.1), located in Zmeinogorsk in Altai Region. The pond was created in the 18th century according to the design of the hydraulic engineer K.D. Frolov in the floodplain of River Zmeevka. This dam flooded the earlier one, which lay upstream, and formed a large reservoir - a pond. The pond is fed by River Zmeevka and precipitation. Its water-surface area is about $7.5 \mathrm{~km}^{2}$. The main source of anthropogenic impact is the exhausted mine, where silver-lead ore was mined in the 1819 centuries.

Sampling points 16 and 17 were located on Lake Beloe (fig.1), which is lying in a wide hollow of the Kolyvan ridge in the Kuryinsky district of the Altai Region at an altitude of $539 \mathrm{~m}$ above sea level. It has a rounded shape and reached $3 \mathrm{~km}$ across. The area of the lake is $2.7 \mathrm{~km}^{2}$, the average depth is $4.5 \mathrm{~m}$. The Beloe belongs to River Loktevka basin, which is the left tributary of River Charysh. A man made channel connects the lake with River Belaya. There is a temporary concrete dam at the mouth of the canal that regulates the flow of water to a particular level. For this reason Lake Beloe belongs to the reservoirs of delayed water exchange and is very susceptible to anthropogenic impact (Yagnachkova, 2008). Lake Beloe is a natural monument since 2010. The company Eco-Vector has been producing sapropel on Lake Beloe since 2013 [8].

Sample number 18 was collected from Lake Bezymyannoe (fig.1), located in the Altai Region in a mountain basin at the foot of the Ivanovo Range, $30 \mathrm{~km}$ from the city of Ridder (Kazakhstan). The lake is closed, has no tributaries. On the western side, the lake adjoins outcrops up to $25-30 \mathrm{~m}$ thick, which can serve as a source of pollution due to wind and water erosion. The lake may also experience anthropogenic load of an existing mining enterprise located in the city of Ridder.

\section{Materials and methods}

Water samples and surface samples of lake sediments were collected at the sampling points (Fig. 1) in order to conduct a rapid assessment of the studied lakes ecological state.

Water samples from large lakes were collected at three different points by using a boat; small lakes were sampled from shores. All samples were divided into two parts, one of which was preserved with concentrated nitric acid to $\mathrm{pH}<2$, and the second was left in its natural state. Unstable indicators such as mineralization and hydrogen index were determined immediately at the place of sampling. The main cations, anions, and also heavy metals in water samples were determined in laboratory conditions.

Lake surface sediments were collected simultaneously with water samples at the same point by using Voronkov sampler. Pollen analysis of lake-bottom sediments were carried out to define lakes catchment area and characteristics of their vegetation. In addition, losses on ignition, the content of organic, inorganic and total carbon, nitrogen, sulfur, $\mathrm{pH}$ level of the aqueous extract, as well as water-soluble, mobile and gross forms of heavy metals were determined in lake sediments $[9,10]$.

Quantitative chemical analysis of collected samples were carried out in the accredited laboratory of the Scientific and Educational Common use center of the Mining University. Metals mass concentrations in the samples were determined by the atomic emission method using an inductively coupled plasma atomic emission spectrometer ICPE-9000 Shimadzu. 
The determination of anions concentrations in the water samples was carried out by ion chromatography using ion-exchange chromatography LC-20 Prominence Shimadzu.

Pollen analysis was carried out at the Institute of Limnology Russian Academy of Sciences. Samples for pollen analysis were processed according to the standard method using heavy liquid. All samples were tested for carbonate content by hydrochloric acid adding. Only one sample, Pond Nagorny sediments, turned out to be low carbonate. The pollen grains and spores identification was carried out according to Kupriyanova and Aleshina, as well as using the Institute of Limnology Russian Academy of Sciences collection. Non-pollen palynomorphs were also determined in each of the samples to reconstruct the state of the lake ecosystem. The green algae Botryococcus braunii and Pediastrum were found. Other algae, fungal spores, plant stomata, microfauna, charcoal, testate amoebae etc. were also found [11].

Quantitative chemical analysis of collected lake sediments samples was carried out in the accredited laboratory of the Scientific and Educational Common use center of the Mining University. Sample preparation of lake sediments consisted of drying, determination of humidity, calcination and determination of losses during calcination. First of all samples were dried on pallets at room temperature in order to obtain an air-dry sample. Then foreign particles (stones, debris, algae, etc.) were removed manually from the sample using tweezers. The homogeneous sample was crushed in an agate mortar for further research. The determination of humidity and losses during calcination was carried out using thermogravianalizer TGA 701 manufactured by Leco $[12,13]$.

During the sample preparation, it was found that Lake Beloe lake sediments are more than $90 \%$ represented by the sand fraction. This is due to the ongoing sapropel production on the lake since 2013. Further chemical analysis of these samples was not carried out, as according to the works of L. Hakanson and W. Gerstner the representative information of water pollution could been obtained only by analyzing the finest particles, which contain the highest concentrations of pollutants. Metals considered as priority lake sediments pollutants.

The decomposition of lake sediments samples was carried out using a microwave system using a mixture of hydrochloric, nitric, hydrofluoric and boric acids in order to determine the gross metal content. Extraction of heavy metals mobile forms was carried out with acetate-ammonium buffer solution with $\mathrm{pH}$ level equal 4.8. Aqueous extracts based on bidistilled water were prepared in order to determine the water-soluble forms of metals [14, 15].

The resulting acid decomposition products and extracts were analyzed using atomic absorption and atomic emission spectrometers. In aqueous extracts, the value of the hydrogen index was also determined.

\section{Results}

According to the results of the analysis, all considered water bodies have low degree of mineralization and neutral $\mathrm{pH}$ level. According to the O.A. Alekin classification, all the studied lakes according to the predominant anion belong to the class of hydrocarbonate; according to the prevailing cation -Lake Ik belongs to the sodium group, and the remaining water bodies - to calcium. Lakes Ik, Kolyvan and Beloe are water bodies of the fishery category of water use; Pond Nagorny and Lake Bezymyannoye - water objects of cultural and domestic purposes. Comparison of the obtained results with the maximum allowable concentrations (MAC) for the corresponding water use categories made it possible to establish excesses on iron in 3 times, manganese - on 9 times, aluminum - on 3 times, and copper on 15 times in water samples from Lake Kolyvan; excesses on manganese in 3 times 
and copper on 30 times in water samples from Lake Beloe; excesses on strontium in 1.5 times and copper in 60 times in water samples from Lake Ik.

There were determined no excesses in water samples from Pond Nagorny and Lake Bezymyannoe, however, this is probably due to more "soft" standards for water objects of cultural and domestic purposes.

Based on the results of pollen analysis, the studied lake landscapes were identified as forest-steppe for Lake Ik and Lake Kolyvan, and as forest for Pond Nagorny and Lake Bezymyannoe (Fig.2).
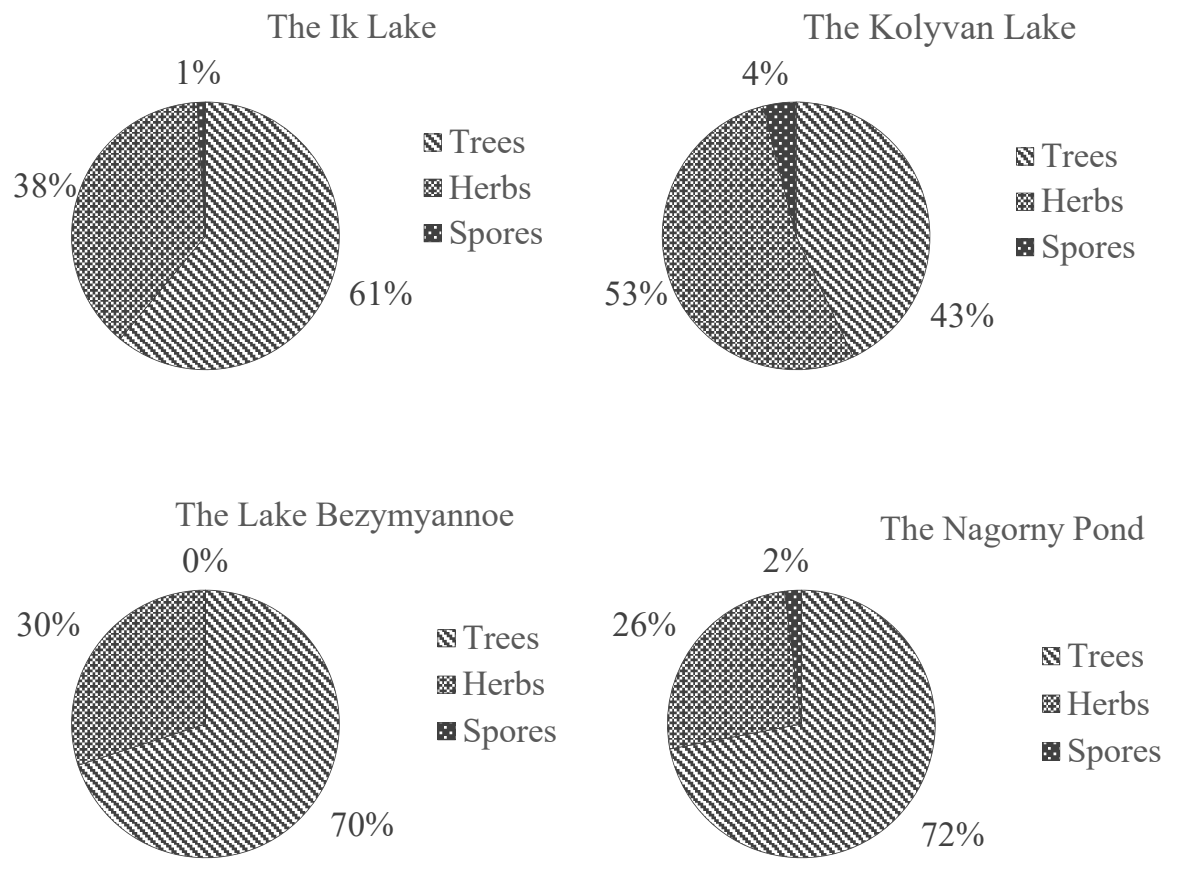

Fig. 2. General pollen spectra composition of the studied lakes samples.

The pollen spectrum of Lake Ik is forest-steppe type and consists of $61 \%$ of trees pollen. Among them, there is much more pollen of Betula and Pinu. At the same time, part of the Pinus pollen is strange. As it known, pine pollen is very volatile and is transported to the maximum distance relative to all other pollen grains. The pollen of Poaceae and Artemisia prevails among grasses pollen (38\%). Among the pollen of ruderal grasses (associated with human activity), -Plantago and Cerealia pollen are noted. Spores are represented by ferns. Among non-pollen palinomorphs, a high content of green algae Pediastrum was found (Fig.3). A lot of microfauna remains, fungal spores, and charcoal were also observed.

For Lake Kolyvan trees pollen content is the lowest and is $43 \%$ with a predominance of Pinus and Betula pollen. At the same time, there is also a drift of pollen. Pollen of grasses, among which Poaceae and Artemisia also predominate, takes the main part in the formation of pollen spectrum here. 


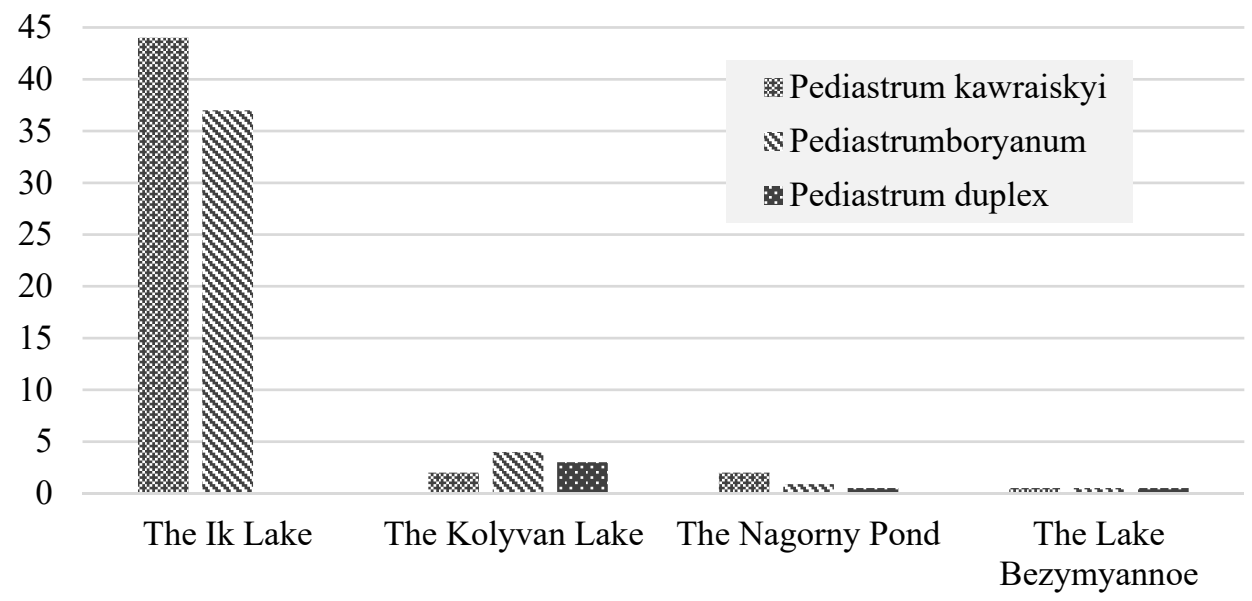

Fig. 3. Pediastrum algae content in the studied lakes.

Pollen of ruderal grasses was observed in small amounts. Also, there is maximum pollen content of aquatic and coastal aquatic plants in this lake. The greatest variety of species is noted among the Pediastrum algae (Fig.3). Botryococcus braunii among green algae and diatoms are also noted. The remains of microfauna, fungal spores and a high percentage of charcoal also were found.

The maximum content of wood pollen was found in Nagorny Pond (72\%) together with the lowest content of grass pollen (26\%). Pinus pollen is absolutely dominant among tree species. In addition, small amounts of Picea and Abies pollen have been also recorded. The percentage of Poaceae pollen is significant. Pollen of ruderal grasses also was determined. Spores are represented by Polypodiacea and Equisetum. The algae are mainly diatoms, and only the Pediastrum species is noted in small numbers among the green ones. The presence of microfauna is very small, very high content of fungal spores and charcoal and testate amoebae.

The pollen content of wood species is also very high in Lake Bezymyannoe (70\%). The amount of Abies and Pinus pollen prevails at total amount of the pollen. The percentage of Picea pollen is not very high. Betula pollen content is quite high. Grass pollen $(30 \%)$ is represented mainly by Poaceae.

The amounts of gross, mobile and water-soluble forms of metals were determined during the chemical analysis of lake sediments. The results are presented in tables 1,2 and 3 (the content of the components is shown in absolutely dry condition).

There are particular methodological difficulties in assessing the degree of lake sediments impact on the ecological state of water bodies [16].

This is primarily due to the fact that there are no standards for lake sediments. According to the Water Code of the Russian Federation, surface water bodies consist of surface waters and the land covered by them within the coastline. Therefore, the obtained amounts of pollutants were compared with the MAC for soils at the first stage of assessing the degree of lake sediments contamination [17-19].

An assessment of only metals gross forms does not provide comprehensive information of the potential contribution of lake sediments into surface water pollution and their migration capacity [20]. The forms of the elements should be taken into consideration when interpreting received results of the analysis lake sediments. 
Table 1. The amounts of gross metal forms in the studied samples of lake sediments.

\begin{tabular}{|c|c|c|c|c|c|c|c|c|c|c|}
\hline \multirow{2}{*}{ Compound } & \multirow{2}{*}{ Units } & \multirow{2}{*}{ MAC } & \multicolumn{8}{|c|}{ Sampling point } \\
\hline & & & 4 & 5 & 6 & 12 & 13 & 14 & 15 & 18 \\
\hline Aluminum & \multirow{15}{*}{$\mathrm{mg} / \mathrm{kg}$} & - & 23950 & 17350 & 27250 & 48269 & 42055 & 44847 & 19624 & 34184 \\
\hline Barium & & - & 190 & 142 & 193 & 341 & 315 & 319 & 1731 & 170 \\
\hline Calcium & & - & 6095 & 6185 & 8875 & 8092 & 7691 & 8840 & 79525 & 32251 \\
\hline Cadmium & & 2.00 & 1.34 & 1.13 & 1.71 & 2.10 & 2.70 & 2.51 & 3.76 & 4.42 \\
\hline Cobalt & & - & 4.9 & 1.3 & 3.1 & 17.8 & 14.8 & 16.7 & 14.3 & 26.8 \\
\hline Chromium & & - & 16.7 & 15.6 & 22.4 & 75.9 & 70.9 & 73.1 & 46.4 & 49.5 \\
\hline Copper & & 132 & 3.01 & 2.74 & 4.91 & 44.0 & 39.8 & 42.0 & 34.3 & 83.2 \\
\hline Iron & & - & 6145 & 5800 & 9105 & 54237 & 51099 & 51121 & 27352 & 46897 \\
\hline Magnesium & & - & 1325 & 1265 & 2385 & 3503 & 3638 & 4064 & 9180 & 4813 \\
\hline Manganese & & 1500 & 159 & 170 & 184 & 490 & 449 & 505 & 785 & 1655 \\
\hline Nickel & & - & 14.2 & 14.2 & 16.7 & 60.5 & 45.8 & 45.7 & 25.2 & 37.6 \\
\hline Lead & & 32 & 7.99 & 8.13 & 7.99 & 10.9 & 6.98 & 7.45 & 4.25 & 4.13 \\
\hline Strontium & & - & 89.1 & 70.3 & 94.3 & 160 & 114 & 119 & 336 & 114 \\
\hline Titanium & & - & 2530 & 2430 & 2610 & 5233 & 5861 & 5067 & 3834 & 4754 \\
\hline Zinc & & 220 & 5.65 & 5.18 & 9.23 & 90.2 & 70.4 & 83.6 & 85.9 & 366 \\
\hline
\end{tabular}

Table 2. The amounts of mobile metal forms in the studied samples of lake sediments.

\begin{tabular}{|c|c|c|c|c|c|c|c|c|c|c|}
\hline \multirow{2}{*}{ Compound } & \multirow{2}{*}{ Units } & \multirow{2}{*}{ MAC } & \multicolumn{8}{|c|}{ Sampling point } \\
\hline & & & 4 & 5 & 6 & 12 & 13 & 14 & 15 & 18 \\
\hline Aluminum & \multirow{15}{*}{$\mathrm{mg} / \mathrm{kg}$} & - & 12.0 & 10.4 & 16.9 & 81.3 & 77.8 & 83.8 & 26.8 & 28.3 \\
\hline Barium & & - & 6.00 & 5.38 & 8.90 & 10.6 & 10.4 & 10.2 & 75.5 & 21.7 \\
\hline Calcium & & - & 1020 & 1888 & 2700 & 4080 & 3975 & 4525 & 76000 & 30250 \\
\hline Cadmium & & - & 0.470 & 0.415 & 0.580 & 1.82 & 0.728 & 0.898 & 1.17 & 1.12 \\
\hline Cobalt & & 5.00 & 0.643 & 0.810 & 1.17 & 1.93 & 1.98 & 1.42 & 3.03 & 5.21 \\
\hline Chromium & & 6.00 & 0.120 & 0.123 & 0.155 & 0.545 & 0.563 & 0.470 & 0.383 & 0.425 \\
\hline Copper & & 3.00 & 0.563 & 0.495 & 0.648 & 2.10 & 1.87 & 1.82 & 2.58 & 11.3 \\
\hline Iron & & - & 59.0 & 56.5 & 109 & 2163 & 1823 & 1963 & 680 & 280 \\
\hline Magnesium & & - & 370 & 258 & 628 & 828 & 868 & 923 & 1775 & 229 \\
\hline Manganese & & 100 & 9.00 & 17.1 & 21.2 & 76.5 & 66.3 & 87.0 & 523 & 303 \\
\hline Nickel & & 4.00 & 0.248 & 0.285 & 0.320 & 3.60 & 2.95 & 2.70 & 1.40 & 1.26 \\
\hline Lead & & 6.00 & 0.260 & 0.252 & 0.283 & 1.10 & 0.875 & 0.675 & 0.325 & 0.282 \\
\hline Strontium & & - & 12.5 & 6.25 & 16.6 & 19.3 & 18.5 & 21.1 & 183 & 34.8 \\
\hline Titanium & & - & 0.913 & 0.933 & 0.928 & 0.980 & 1.01 & 0.970 & 0.520 & 0.573 \\
\hline Zinc & & 23.0 & 2.16 & 1.44 & 1.35 & 7.35 & 6.10 & 6.93 & 7.08 & 72.0 \\
\hline
\end{tabular}


Table 3. The amounts of water-soluble metal forms in the studied samples of lake sediments.

\begin{tabular}{|c|c|c|c|c|c|c|c|c|c|}
\hline \multirow{2}{*}{ Compound } & \multirow{2}{*}{ Units } & \multicolumn{8}{|c|}{ Sampling point } \\
\hline & & 4 & 5 & 6 & 12 & 13 & 14 & 15 & 18 \\
\hline Aluminum & \multirow{15}{*}{$\mathrm{mg} / \mathrm{kg}$} & 11.0 & 10.0 & 13.0 & 15.4 & 0.368 & 0.918 & 25.5 & 13.2 \\
\hline Barium & & 0.953 & 0.625 & 1.26 & 1.76 & 1.61 & 1.63 & 1.13 & 0.673 \\
\hline Calcium & & 221 & 495 & 768 & 1418 & 1020 & 1061 & 1508 & 1093 \\
\hline Cadmium & & 0.175 & 0.098 & 0.238 & 0.210 & 0.118 & 0.155 & 0.120 & 0.095 \\
\hline Cobalt & & 0.225 & 0.375 & 0.575 & 0.530 & 0.730 & 0.260 & 0.203 & 0.280 \\
\hline Chromium & & 0.052 & 0.053 & 0.070 & 0.009 & 0.012 & 0.007 & 0.088 & 0.060 \\
\hline Copper & & 0.110 & 0.010 & 0.118 & 0.221 & 0.185 & 0.201 & 0.483 & 0.753 \\
\hline Iron & & 10.7 & 7.50 & 25.5 & 1.03 & 0.810 & 0.821 & 36.8 & 10.9 \\
\hline Magnesium & & 82.5 & 159 & 249 & 123 & 146 & 171 & 115 & 76.3 \\
\hline Manganese & & 0.380 & 0.465 & 0.480 & 20.5 & 16.1 & 20.7 & 1.41 & 0.775 \\
\hline Nickel & & 0.058 & 0.073 & 0.085 & 0.192 & 0.180 & 0.175 & 0.180 & 0.150 \\
\hline Lead & & $<0.25$ & $<0.25$ & $<0.25$ & $<0.25$ & $<0.25$ & $<0.25$ & $<0.25$ & $<0.25$ \\
\hline Strontium & & 3.85 & 1.70 & 5.68 & 5.15 & 4.10 & 4.68 & 12.53 & 2.60 \\
\hline Titanium & & 0.888 & 0.895 & 0.875 & 0.198 & 0.160 & 0.183 & 0.275 & 0.295 \\
\hline Zinc & & 0.085 & 0.050 & 0.038 & 1.16 & 0.923 & 0.940 & 0.253 & 0.240 \\
\hline $\mathrm{pH}$ & $\mathrm{pH}$ units & 6.23 & 6.69 & 7.05 & 6.60 & 6.16 & 6.31 & 7.17 & 6.88 \\
\hline
\end{tabular}

The mobile and water-soluble forms of pollutants of lake sediments could be the potential source of the water bodies secondary pollution as a result of wind uplifting, changes in redox conditions, increased activity of microorganisms and etc. Therefore, special attention was paid to assessing the level of mobile and water-soluble forms of heavy metals pollution [21, 22].

Mobile forms of metals make up a high percentage of the total content in Lake Kolyvan, Pond Nagorny and Lake Bezymyannoye, which indicates that lake sediments are a source of secondary pollution of the studied water bodies.

\section{Discussion}

According to pollen analysis and non pollen palynomorphs analysis, the most unfavorable conditions for the development of the lake and surrounding landscapes were identified for Lake Bezymyannoye in Kazakhstan. The most favorable conditions were identified for Lake Ik in the southern part of the West Siberian lowland. This is evidenced by the content and composition of macrophytes, the content and composition of grasses and tree species associated with human activities and settlements. The presence of a large spread of fungal spores may also be due to anthropogenic influence [23-25].

To determine the degree and nature of the studied lake sediments contamination, the lake sediments accumulation coefficient (BSAC) was used, which was calculated using the formula:

$$
\mathrm{BSAC}=\frac{\mathrm{C}_{1}}{\mathrm{C}_{2}},
$$

where: $C_{1}-$ the concentration of pollutants in the lake sediments, $\mu \mathrm{g} / \mathrm{g} ; \mathrm{C}_{2}-$ the concentration of pollutants in water at the same period of time, $\mu \mathrm{g} / \mathrm{dm}^{3}$. 
The results of calculating the lake sediments accumulation coefficients are presented in graphical form in Figure 4.
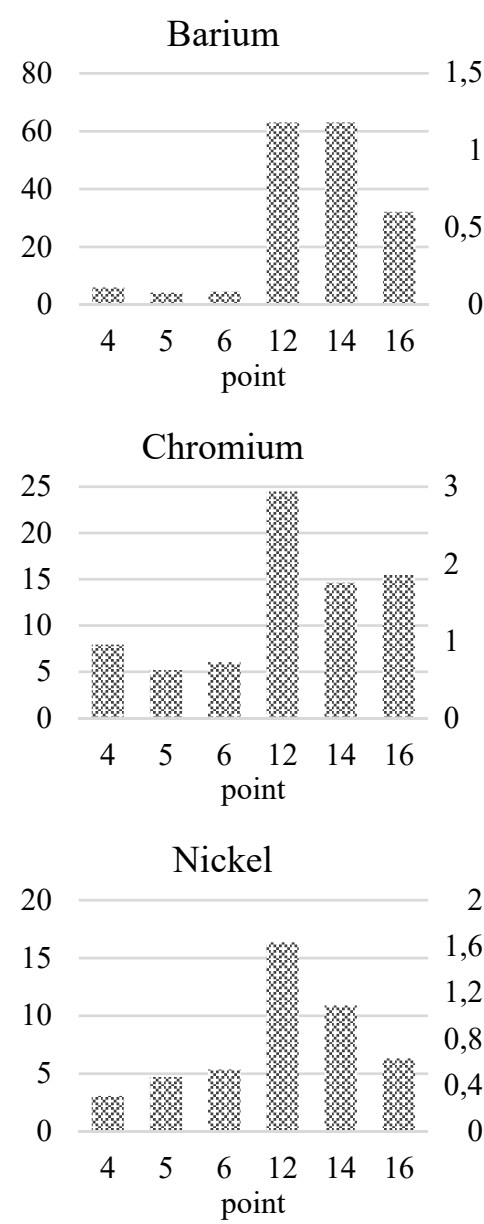

Cadmium

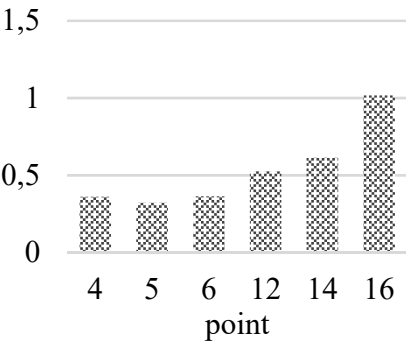

Copper

3
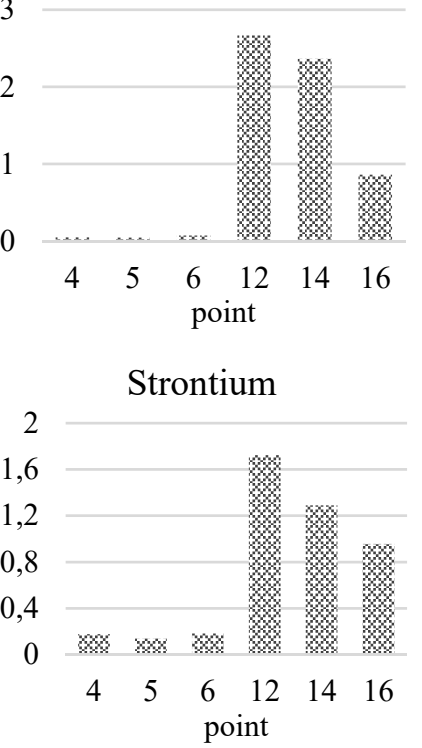

Cobalt
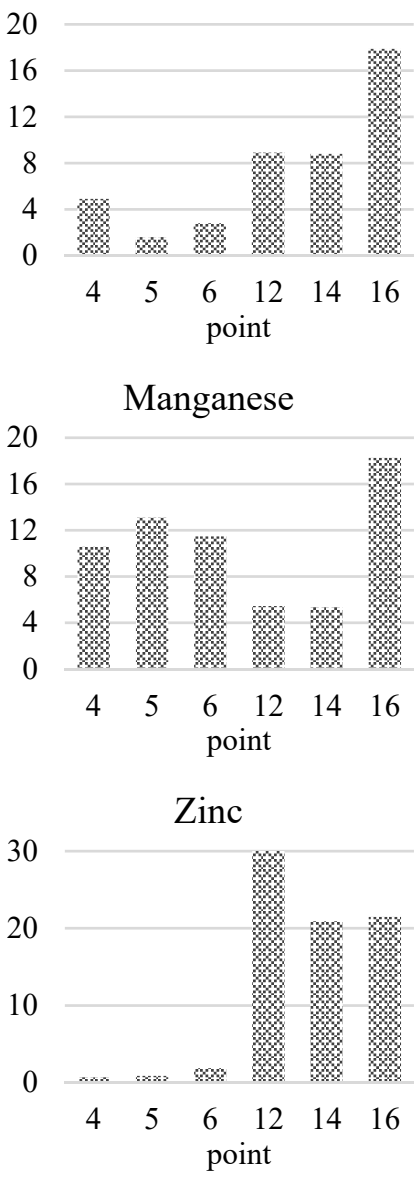

Fig. 4. General pollen spectra composition of the studied lakes samples.

Figure 4 shows that Lake Ik has the lowest level of chronic pollution from all examined lakes (point 4 - point 6). The BSAC values for Lake Ik for all heavy metals except manganese are within $\mathrm{n}$ (where $\mathrm{n}=$ from 1 to 10 ), which, along with low concentrations of pollutants in water and lake sediments, characterizes the situation in the water body as satisfactory.

It was found that Lake Kolyvan suffers from significant anthropogenic impact. This fact is evidenced by the BSAC values in the range $n \cdot 10-n \cdot 102$ for nickel, zinc and barium. In addition, excesses of maximum allowable concentrations in water for iron in 3 times, manganese - on 9 times, aluminum - on 3 times, and copper on 15 times indicate the entry into water object of recent pollution.

High BSAC values for Pond Nagorny are observed for barium, zinc, cobalt and manganese, which is most likely due to the waters infiltration from the mined mine [26]. This water body can be characterized as slightly polluted according to BSAC values.

The nature of the pollutant, its solubility in water, specific gravity, the specificity of the sorption-desorption processes in the system "water - lake sediments" and geomorphological features of the water body are the factors, which also affect the BSAC values. 
The total pollution index (ZC) is a widely used criterion, along with the BSAC, for assessing the anthropogenic impact on lake sediments [27, 28]. It was calculated for each sampling point for all analyzed heavy metals:

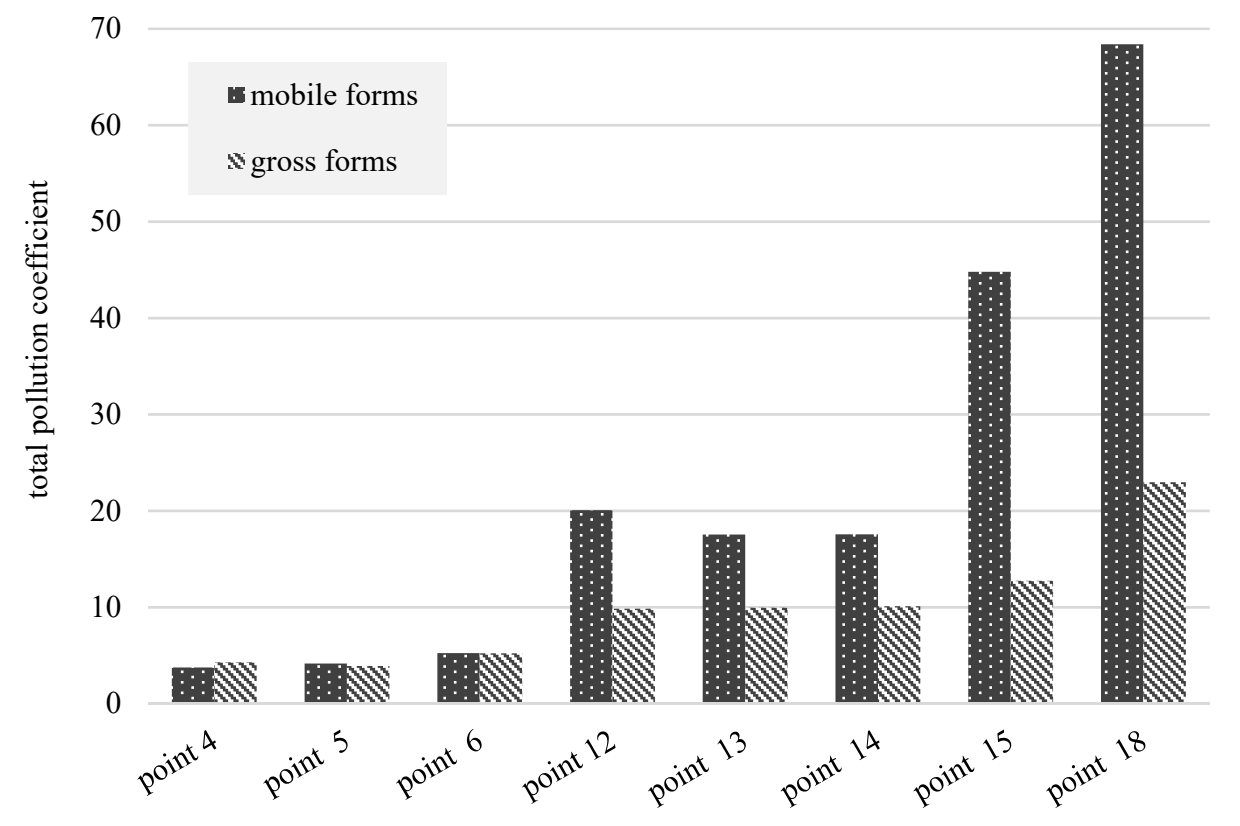

Fig. 5. Coefficients of total contamination of lake sediments by metals gross and mobile forms.

$$
\mathrm{Z}_{\mathrm{C}}=\sum_{\mathrm{i}=1}^{\mathrm{n}} \mathrm{C}_{\mathrm{C}} \cdot(\mathrm{n}-1) \text {, }
$$

where, $\mathrm{C}_{\mathrm{C}}$ - contrast ratio; $\mathrm{n}$ - the number of elements.

The calculation of contrast coefficients $\left(\mathrm{C}_{\mathrm{C}}\right)$ is performed using the formula:

$$
\mathrm{C}_{\mathrm{C}}=\frac{\mathrm{C}_{\mathrm{i}}}{\mathrm{C}_{\mathrm{f}}}
$$

where, $\mathrm{C}_{\mathrm{i}}$ and $\mathrm{C}_{\mathrm{f}}$ - concentrations of the contaminant in the study and background areas, corresponding.

To calculate contrast coefficients, the maximum allowable concentrations for soils was used as background values (table 1-2). The results of calculating the total indicators of contamination $(\mathrm{Zc})$ of lake sediments by metals gross and mobile forms are shown in figure 5 .

The coefficients of total contamination of lake sediments by heavy metals (Fig. 5) make it possible to make the following conclusion according to the methodology of Y.E. Saet. Lake Ik (point 4 - point 6) is a water object with a low level of pollution, The Lake Kolyvan (point 12 - point 14) is a water object with medium level of pollution, Nagorny Pond (point 15) and The Lake Bezymyannoye (point 18) are water objects with a high level of pollution [29].

High values of the total indexes of Pond Nagorny and Lake Bezymyannoe pollution characterize their lake sediments as a dangerous source of secondary pollution and indicate their high toxicity to hydrobionts. 


\section{Conclusion}

As a result of the studies, the preliminary ecological state of water bodies in the southern part of Western Siberia, Altai Region and Eastern Kazakhstan was assessed. Chemical analysis results of water samples and lake sediments revealed a significant technogenic load on The Nagorny Pond and The Lake Bezymyannoye, which are characterized by a high level of pollution. It is primarily associated with their location near existing or used mines. The data of pollen analysis and non-pollen palynomorphs analysis confirm these results.

Lake Kolyvan and Lake Beloe are classified as water bodies with medium level of pollution. Increased content of heavy metals mobile forms, compared with the gross ones in Lake Kolyvan lake sediments, indicate insufficient self-cleaning ability of the reservoir, which in the future, along with an increasing recreational load, will lead to a sharp deterioration in the ecological state of the lake.

Lake Ik has the most favorable ecological state of the studied lakes. The highest content of Pediastrum algae is also noted for this lake, which indicates a low level of anthropogenic impact and high self-cleaning ability of it.

The conducted studies confirm the possibility of rapid assessment of regions ecological condition using a new method, which consists in lakes studying using spore-pollen and geochemical analyzes of the upper layer of lake sediments of lakes. This method does not imply a thorough study of the causes of pollution but allowed to get a quick preliminary assessment.

\section{References}

1. T. Efremova, A. Sabylina, P. Lozovik, V. Slaveykova, M. Zobkova, Inland Waters 9(2), 227-238 (2019)

2. M. Chukaeva, V. Povarov, I. Sverchkov, Moscow University Chemistry Bulletin 75(1), 36-42 (2020)

3. M.A. Pashkevich, T.A. Petrova, I.P. Sverchkov, Obogashchenie Rud 1, 46-50 (2017)

4. A.A. Poznyakov, News of the Altai Branch of the Russian Geographical Society 3(38), 93-98 (2015)

5. O.P. Nikolaeva, Altai: ecology and nature management, 95-100 (2005)

6. N.G. Prudnikova, Recreational nature management, tourism and sustainable development of regions, 269-272 (2007)

7. M.A. Chukaeva, V.A. Matveeva, Water Resources 45(6), 935-940 (2018)

8. G.V. Korobkova, Encyclopedia of the Altai Territory 2, 67 (1996)

9. K. Hlavcova, S. Kohnova, Y. Veliskova, Journal of Hydrology and Hydromechanics 66(4), 404-415 (2018)

10. A.E. Isakov, International Journal of Ecology and Development 31(2), 90-98 (2016)

11. L. Hakanson, Water Recourses 20(1), 41-46 (1984)

12. A.E. Isakov, V.A. Matveeva, M.A. Chukaeva, Journal of Ecological Engineering 19(1), 42-47 (2018)

13. E. Konovalova, International Multidisciplinary Scientific GeoConference SGEM 18(5.2), 35-40 (2018)

14. Z. Liu, Y. Li, Y. Xiao, Environmental Earth Sciences 1, 37 - 42 (2017)

15. V.A. Matveeva, M.A. Chukaeva, I.P. Sverchkov, Journal of Physics: Conference Series 1384(1), 012028 (2019) 
16. M. Myrzakhmetov, S.M. Umbetova, A.K. Mukhatova, Bulletin of KazNTU 3(103), 130-132 (2007)

17. O. Palagushkina, L. Frolova, E. Zinnatova, International Multidisciplinary Scientific GeoConference SGEM 18(5.1), 283-288 (2018)

18. M.A. Pashkevich, I.P. Sverchkov, M.A. Chukaeva, Obogashchenie Rud 6, 54-57 (2017)

19. C. Vale, Science of the Total Environment, 97-98 (1990)

20. V.A. Matveeva, A.E. Isakov, I.P. Sverchkov, Innovation-Based Development of the Mineral Resources Sector: Challenges and Prospects - 11th conference of the RussianGerman Raw Materials, 431-436 (2019)

21. N.I. Yagnachkova, Altai territory is proud of this: based on the materials of a creative competition, 24-26 (2008)

22. M.V. Bykova, M.A. Pashkevich, V.A. Matveeva, I.P. Sverchkov, Topical Issues of Rational Use of Natural Resources - Proceedings Of The International Forum-Contest of Young Researchers, 347-359 (2019)

23. M. Trapote, T. Vegas-Vilarrúbia, P. Lopez, E. Puche, Palaeogeography, Palaeoclimatology, Palaeoecology 496, 292-304 (2018)

24. K. Apolinarska, K. Pleskot, A.Pelechata, M. Migdale, Journal of Paleolimnology 63, 283-304 (2020)

25. A.S. Plokhov, M.A. Pashkevich, A.E. Isakov, M.A. Chukaeva, Topical Issues of Rational Use of Natural Resources - Proceedings Of The International Forum-Contest of Young Researchers, 379-386 (2019)

26. E. Singovszka, P. Pavlikova, M. Balintova, International Multidisciplinary Scientific GeoConference: SGEM 17, 681-688 (2017)

27. M. Kolpakova, O. Gaskova, O. Naymushina, S. Krivonogov, Bulletin of the Tomsk Polytechnic University, Geo Assets Engineering, 329, 111-123 (2018)

28. V.A. Matveeva, T.A. Petrova, M.A. Chukaeva, Obogashchenie Rud 2, $42-47$ (2018)

29. M. Semenov, Yu. Semenov, V. Snytko, A. Silaev, Geography And Natural Resource 2, 69-76 (2019) 